\title{
Factors Associated With Treatment Delay in Breast Cancer: A Prospective Study
}

Raja Rahool ${ }^{1}$, Ghulam Haider ${ }^{1}$, Muhammad Hayat ${ }^{1}$, Mehwish R. Shaikh ${ }^{1}$, Paras Memon ${ }^{1}$, Bhunisha Pawan ${ }^{1}$, Kiran Abbas ${ }^{2}$

1. Oncology, Jinnah Postgraduate Medical Centre, Karachi, PAK 2. Medicine, Jinnah Postgraduate Medical Centre, Karachi, PAK

Corresponding author: Kiran Abbas, kiranabbas2020@gmail.com

\section{Abstract}

\section{Introduction}

The frequency of breast cancer $(\mathrm{BC})$ is increasing among Pakistani females. It has been estimated that one out every nine women is predicted to develop $\mathrm{BC}$, which is the highest disease occurring rate in the Asian population. The study aimed to evaluate the factors responsible for delay in diagnosis of BC in Sindh, Pakistan.

\section{Methodology}

This study was conducted at the Medical Oncology Department of Jinnah Postgraduate Medical Center Karachi from December 2018 to June 2019. All women between 17 and 80 years diagnosed with BC who had treatment delay of more than six months were included in the study using a non-probability consecutive sampling technique. The face-to-face interviews were conducted by the researcher himself and all the data regarding demographics and factors related to treatment delay of $\mathrm{BC}$ was noted in a structured questionnaire. Data were analyzed using SPSS version 23 (IBM Corp., Armonk, NY).

\section{Results}

Appointment delay was significantly associated with a treatment-seeking delay in patients ( $\mathrm{p}=0.03)$. Lack of awareness was another significant factor associated with treatment delay in BC patients. About 50 (70.4\%) women who reported a lack of awareness sought treatment after 10 months of their first onset of symptoms $(\mathrm{p}=0.001)$. Cultural beliefs were a significant cause of treatment delay of $10-12$ months in $71.8 \%$ of patients $(\mathrm{p}=0.021)$. Financial constraints significantly correlated with treatment delay $(\mathrm{p}=0.015)$.

\section{Conclusion}

The cultural beliefs, poor financial status, and lack of awareness are the significant factors for the treatment delay in BC patients. Promoting female health awareness can tackle many of these issues.

Review began 02/06/2021 Review ended 02/07/2021 Published 02/09/2021

\section{() Copyright 2021}

Rahool et al. This is an open access article distributed under the terms of the Creative Commons Attribution License CC-BY 4.0., which permits unrestricted use, distribution, and reproduction in any medium, provided the original author and source are credited.
Categories: General Surgery, Oncology, Epidemiology/Public Health

Keywords: breast neoplasms, breast carcinoma, financial stress, fear, delayed treatment, time-to-treatment, patient care, breast tumors

\section{Introduction}

Breast cancer (BC) is the commonest cancer, a major global health issue, and a leading cause of death among females. The occurrence rate of BC is rising globally, but the survival rate is better in developed countries due to diagnosis at an early stage and advanced treatment [1,2]. About 1,000,000 females are yearly diagnosed having $\mathrm{BC}[2]$.

The frequency of $\mathrm{BC}$ is increasing among Pakistani females. It has been estimated that one out every nine women is predicted to develop $\mathrm{BC}$, which is the highest disease occurring rate in the Asian population $[2,3]$. People of all ages are influenced by cancer and it is creating a huge social and financial burden on the residents of Pakistan [2]. Most of the areas of Pakistan are underprivileged and the majority of the population resides in rural areas [2]. BC accounts for 32\% of all tumors in women of Karachi [4].

The chances of improvement, cure, quality of life, and survival are highly related to early diagnosis and detection of BC and onset of treatment. A delay in diagnosis may lead to advanced stages of tumor $[5,6]$. It is speculated that in Pakistan, social-cultural concerns, improper access to healthcare facilities, unavailability of diagnostic tools, illiteracy or low education, lack of awareness about signs and symptoms of BC, low socioeconomic status, and use of traditional therapy and false beliefs among females could lead to treatment delay resulting in poorer prognosis at presentation [7-9]. 
More than half of the females presented late with an advanced stage of BC, i.e., 3 or 4 in Pakistan [10]. The delay in treatment of $\mathrm{BC}$ after the appearance of signs and symptoms can be decreased by identifying potential factors related to the delay. Therefore, the present research was carried out to identify the risk factors responsible for treatment delay of patients with BC. This research would be helpful for the early management and treatment of patients with $\mathrm{BC}$, promotion of health education among females, improved survival rates, and better prognosis of $\mathrm{BC}$ patients.

\section{Materials And Methods}

A prospective observational study was conducted at the Medical Oncology Department of Jinnah Medical Postgraduate Center from December 10, 2018, to June 10, 2019, and it was an observational analytical study. The sample size was estimated using Open epi online sample size calculator by taking the frequency of factor associated with treatment delay of BC, i.e., negative physical breast examination as $24.4 \%$ [11], the margin of error as $6 \%$, and $95 \%$ confidence level, the calculated sample size came out as 197 . All the females of age 17-80 years diagnosed with $\mathrm{BC}$ who had treatment delay of more than 6 months were included in the study using a non-probability consecutive sampling technique. Women with psychiatric problems and who did not give consent were excluded from the study.

After taking approval from the ethical review committee data was collected. Informed written or verbal consent was taken from all the eligible patients. The face-to-face interviews were conducted by the researcher himself and all the data regarding demographics and factors related to treatment delay of BC was noted in a structured questionnaire.

Data was entered and analyzed using SPSS version 23 (IBM Corp., Armonk, NY). Quantitative variables were presented as mean and SD whereas qualitative variables were presented as frequency and percentage. Oneway ANOVA was applied to address the delay time with factors related to treatment delay. A p-value $\leqslant$ of 0.05 was taken as statistically significant.

\section{Results}

A total of 197 patients were included in the study. The age of the patients was $45.38 \pm 11.58$ years. The mean BMI was reported as $26.28 \pm 5.49 \mathrm{~kg} / \mathrm{m}^{2}$. The majority of the patients were living in urban areas ( $\mathrm{n}=139$, $70.6 \%)$ whereas 58 patients $(29.4 \%)$ were living in rural areas. Most of them were illiterate $(n=103,52.3 \%)$, belonged from low class $(n=149,75.6 \%)$, housewives $(n=168,85.3 \%)$ and married $(n=126,64 \%)$ as shown in Table 1 . 


\section{Cureus}

\begin{tabular}{|c|c|}
\hline Characteristics & Mean \pm SD \\
\hline Age (years) & $45.38+11.58$ \\
\hline \multirow[t]{2}{*}{ BMI $\left(\mathrm{kg} / \mathrm{m}^{2}\right)$} & $26.28 \pm 5.49$ \\
\hline & $n(\%)$ \\
\hline \multicolumn{2}{|l|}{ Residence } \\
\hline Urban & $139(70.6)$ \\
\hline Rural/metropolitan & 58 (29.4) \\
\hline \multicolumn{2}{|l|}{ Education } \\
\hline Illiterate & $103(52.3)$ \\
\hline Matric & $14(7.1)$ \\
\hline Primary & 39 (19.8) \\
\hline Intermediate & $30(15.2)$ \\
\hline Graduate & $10(5.1)$ \\
\hline Postgraduate & $1(0.5)$ \\
\hline \multicolumn{2}{|l|}{ Socioeconomic status } \\
\hline Low class (income: $<15,000$ rupees) & $149(75.6)$ \\
\hline Middle class (income: 15,000-30,000 rupees) & $33(16.8)$ \\
\hline High class (income: $>30,000$ rupees) & $15(7.6)$ \\
\hline \multicolumn{2}{|l|}{ Occupation } \\
\hline Student & $5(2.5)$ \\
\hline Housewife & $168(85.3)$ \\
\hline Employed & $23(11.7)$ \\
\hline Unemployed & ${ }_{1(0.5)}$ \\
\hline \multicolumn{2}{|l|}{ Marital Status } \\
\hline Married & $126(64)$ \\
\hline Separated & $15(7.6)$ \\
\hline Single & $11(5.6)$ \\
\hline Widow & $45(22.8)$ \\
\hline
\end{tabular}

TABLE 1: Sociodemographic characteristics of the study population.

According to factors associated with treatment delay, almost more than half of the patients had financial constraints 105 (53.3\%). 86 (43.7\%) women informed us about the lack of support (like moral, financial, and social support). 71 (36.0\%) women had a lack of awareness or misconception regarding treatment and 59 (29.9\%) women had treatment delay due to inaccessibility to healthcare. About 43 (21.8\%) women had fears of social embarrassment regarding the treatment of disease, 39 (19.8\%) did not seek treatment due to cultural beliefs, and 38 (19.3\%) women had avoided treatment due to the unavailability of a female doctor. Approximately 39 (19.8\%) females were presented late due to prior use of traditional methods such as unconventional and herbal therapy. Twelve women (6.1\%) had appointment delays; 11 (5.6\%) women had concerns regarding cosmetic disfigurement as described in Figure 1. 


\section{Cureus}

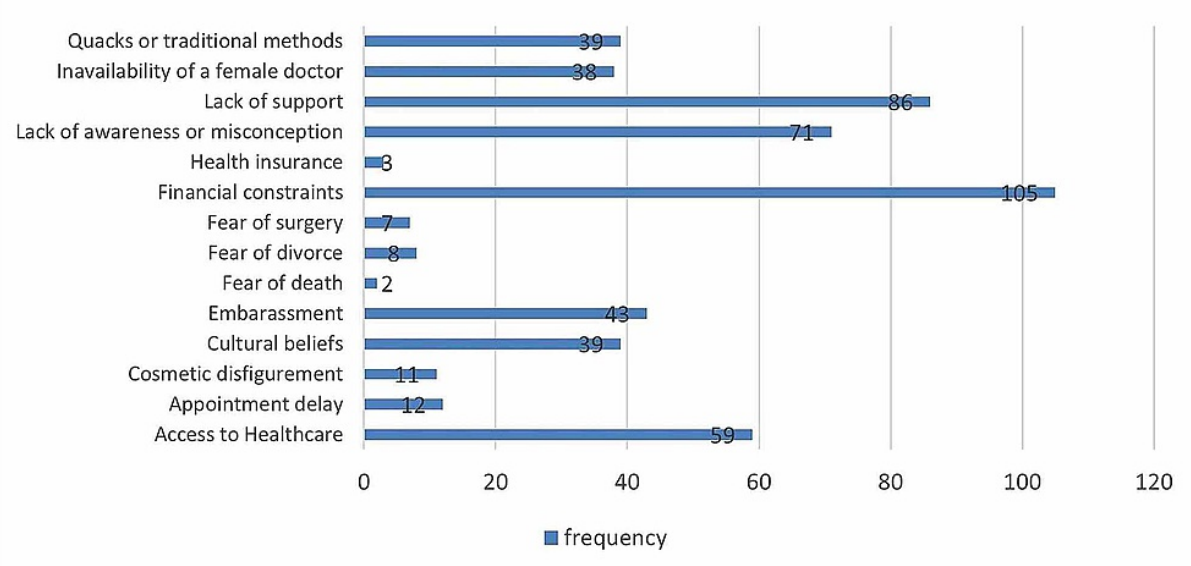

\section{FIGURE 1: Factors associated with treatment delay in patients with}

breast cancer.

Appointment delay was significantly associated with the treatment-seeking delay in patients $(\mathrm{p}=0.03)$. Lack of awareness was another significant factor associated with treatment delay in BC patients. About 50 (70.4\%) women who reported a lack of awareness sought treatment after 10 months of their first onset of symptoms ( $\mathrm{p}=0.001)$. Cultural beliefs were a significant cause of treatment delay of $10-12$ months in $71.8 \%$ of patients $(\mathrm{p}=0.021)$. Financial constraints significantly correlated with treatment delay $(\mathrm{p}=0.015)$. Over one-half of the patients with financial constraints had treatment delays of more than nine months. See Table 2 for details.

\begin{tabular}{|c|c|c|c|}
\hline \multirow{2}{*}{ Factors } & \multicolumn{2}{|l|}{ Duration of delay } & \multirow{2}{*}{$\mathrm{p}$-value } \\
\hline & 6-9 months $(n=91)$ & 10-12 months ( $n=106)$ & \\
\hline \multicolumn{4}{|c|}{ Traditional methods } \\
\hline Yes & $16(47.1 \%)$ & $18(52.9 \%)$ & 0.911 \\
\hline No & $75(46 \%)$ & $88(54 \%)$ & \\
\hline \multicolumn{4}{|c|}{ Appointment delay } \\
\hline Yes & $3(25.0 \%)$ & $9(75.0 \%)$ & 0.03 \\
\hline No & $105(56.8 \%)$ & $80(43.2 \%)$ & \\
\hline \multicolumn{4}{|c|}{ Lack of awareness } \\
\hline Yes & $21(29.6 \%)$ & $50(70.4 \%)$ & 0.001 \\
\hline No & $66(33.5 \%)$ & $60(30.4 \%)$ & \\
\hline \multicolumn{4}{|c|}{ Fear of surgery } \\
\hline Yes & $3(42.9 \%)$ & $4(57.1 \%)$ & 0.857 \\
\hline No & $88(46.3 \%)$ & $102(53.7 \%)$ & \\
\hline \multicolumn{4}{|c|}{ Fear of death } \\
\hline Yes & 0 & $2(100 \%)$ & 0.188 \\
\hline No & $91(46.7 \%)$ & 104(53.3\%) & \\
\hline \multicolumn{4}{|c|}{ Fear of divorce } \\
\hline Yes & $2(25 \%)$ & $6(75 \%)$ & 0.291 \\
\hline No & $89(47.1 \%)$ & $100(52.9 \%)$ & \\
\hline \multicolumn{4}{|c|}{ Cultural beliefs } \\
\hline Yes & $11(28.2 \%)$ & $28(71.8 \%)$ & 0.021 \\
\hline
\end{tabular}




\section{Cureus}

No

Unavailability of a female doctor

Yes

No

Financial constraints

Yes

No

Access to healthcare

Yes

No

Embarrassment

Yes

№

Lack of support

Yes

No

Quacks or herbal treatment

Yes

No

Health insurance

Yes

No

Cosmetic disfigurement

Yes

No
$80(50.6 \%)$

$16(42.1 \%)$

$75(47.2 \%)$

$40(38.1 \%)$

$51(55.4 \%)$

$27(45.8 \%)$

$64(46.4 \%)$

$18(41.9 \%)$

$73(47.4 \%)$

$35(40.7 \%)$

$56(50.5 \%)$

$16(42.1 \%)$

$73(45.9 \%)$

$1(33.3 \%)$

$90(46.4 \%)$

6(54.5\%)

$85(45.7 \%)$
78(49.4\%)

$22(57.9 \%)$

0.574

$84(52.8 \%)$

$65(61.9 \%)$

0.015

$41(44.6 \%)$

$32(54.2 \%)$

$74(53.6 \%)$

25(58.1\%)

0.519

$81(52.6 \%)$

$51(59.3 \%)$

0.173

$55(49.5 \%)$

$22(57.9 \%)$

0.672

$86(54.1 \%)$

$2(66.7 \%)$

0.99

$104(53.6 \%)$

$5(45.5 \%)$

0.757

$101(54.3 \%)$

TABLE 2: Factors related to treatment in association with duration of delay.

\section{Discussion}

The morbidity and mortality rate of BC patients is directly associated with a delay in the treatment of patients [12]. This research was conducted to identify the factors behind the delay in the treatment of BC in our country. By understanding the reasons for delay it might be helpful in reducing the delay time and early detection of disease.

Patients with BC presenting late is the important contributing factor for treatment delay. Our findings correspond with the previous literature. A study by Maghous et al. found about $70 \%$ of the females presented late for the treatment due to personal reasons and $72 \%$ of the females with symptoms of BC had a delay of more than 6 months [11]. Talpur et al. in their study found approximately 95\% of females took medical consultation after six months of diagnosis and 38\% of the females presented with stage 3 of tumor [13]. In another similar study conducted by Gulzar et al. found $89 \%$ of the females presented late after a delay of more than three months for treatment [7]. Baig et al. observed in their study that means delay was 8.1 months and almost $66 \%$ of the patients were presented with a delay of more than six months [14].

In the present study, the mean of the patients was 45.38 years at the time of diagnosis. Almost the same result, the mean age of 44.1 years has been observed in the study in Pakistan by Gulzar et al. [7.] Whereas a study conducted in India showed a higher mean age of the patients such as 51.05 years at the time of 
diagnosis [15]. In the present study, $70.6 \%$ of the patients were living in urban areas and most of them were illiterate (52.3\%) and belonging to the low class (75.6\%). We also found that most of the females were married and housewives. A similar study conducted by Khan MA et al. also found that majority of the females were of age more than 40 years, had education less than 8 years, and belonged from poor and low socio-economic class and married [10]. Similar results were found by Gulzar et al. in their study [7]. In a Malaysian study by Norsaadah et al., most of the females were married and housewives, however education level is slightly more up to high school education among them [16]. In the present study, $70.6 \%$ of the females were from urban areas as this study was conducted at the tertiary care hospital of Karachi. In a study conducted at Rawalpindi and Islamabad about $69 \%$ of the females belonged from rural areas, $95 \%$ were married and approximately $82 \%$ had low-income levels [17].

In the present study, $53.3 \%$ of women had financial constraints followed by lack of support (43.7\%), lack of awareness regarding treatment (30.5\%), and inaccessibility to healthcare. The reason behind the high frequency of these factors is low-income level, illiteracy, and residence away from specialized healthcare. The majority of the Pakistani population has low-income levels due to which high fees of educational institutes are unaffordable for them. In the present study, many other factors such as cultural beliefs and prior use of traditional methods were identified as contributing factors for delay in treatment of BC due to limited education. The misconceptions that a person having cancer cannot survive and there is no treatment available are very common among the Pakistani populace. Therefore the lack of awareness and support are highly associated with treatment delay in patients with BC $[18,19]$. The study by Ayaz et al. reported $62.3 \%$ of the females presented late because they were unaware of the treatment of $\mathrm{BC}$ [17].

Gulzar et al. in their study found that $96 \%$ of the females presented late because they ignore the symptoms and painless lump in the breast, $81 \%$ had fear related to treatment expenses, $73 \%$ were shy to be treated by a male doctor, $71 \%$ had prior use of traditional methods, $65 \%$ had a social stigma, $61 \%$ were used to visit spiritual healers and 37\% women had inaccessibility to healthcare [7]. A study by Shamsi et al. found patients presented late due to lack of awareness (58.1\%), he also found $16.1 \%$ of the patients had embarrassment, misconceptions, fears, and shame related to the treatment of $\mathrm{BC}$ and $9.2 \%$ of the females were delay due to alternative medicine/ traditional method and had other reasons like financial constraints, family commitments and husband reaction to BC [20].

The social taboos such as embarrassment and shyness of females when discussing health-related concerns of the breast also causes a delay in treatment of BC. Most of them use alternative medicines (72\%) for treatment, they don't pay attention to indications of BC and seek medical advice from quacks or spiritual healers rather than oncologists [7,21]. In the present study factors such as social embarrassment regarding disease diagnosis in $21.8 \%$ of women, avoided treatment due to pardah (veil) among $19.3 \%$ women, appointment delay due to unavailability of consultant among $6.1 \%$ women, concern regarding cosmetic disfigurement among $5.6 \%$ women, anxiety related to divorce in $4.1 \%$ and surgery in $3.6 \%$ were observed. Other factors such as prior visits to quacks, no health insurance, and fear of death contributed a very less proportion in the delay of treatment of BC. Studies found that anxiety related to cancer treatment caused delays among $12 \%$ of women in developing countries [22,23]; specifically in patients with positive BC family history (82\%). The wrong information regarding the adverse effects and chemotherapy toxicity directed to refusal and fear of treatment as well. Anxiety regarding separation or remarriage of the spouse also directed some women to take decisions against the treatment of BC. The belief that surgery or treatment causes disability and disfigurement is also related to the late presentation of BC [24].

There is a dire need for health education and health promotion among females of both rural and urban areas of Pakistan. The accessibility to healthcare should be improved which could increase the cure rate at the early stage of the tumor. The government and NGOs should also play a role by making policy for the treatment of $\mathrm{BC}$ and funds should be arranged for unaffordable patients. In the long term, these efforts will decrease the prevalence and increase the survival rate of BC patients in Pakistan.

\section{Conclusions}

The results of the present study have identified that cultural beliefs, poor financial status, appointment delay, and lack of awareness are the significant factors for the treatment delay in BC patients. There is a dire need for health education and health promotion among females of both rural and urban areas of Pakistan. The screening test should be made available and cost-effective for patients having low-income levels.

\section{Additional Information \\ Disclosures}

Human subjects: Consent was obtained or waived by all participants in this study. College of Physicians and Surgeons Pakistan issued approval CPSP/Onc/273/2020. The submitted study with serial: CPSP/Onc/273/2020 has been approved for study. Animal subjects: All authors have confirmed that this study did not involve animal subjects or tissue. Conflicts of interest: In compliance with the ICMJE uniform disclosure form, all authors declare the following: Payment/services info: All authors have declared that no financial support was received from any organization for the submitted work. Financial relationships: All 
authors have declared that they have no financial relationships at present or within the previous three years with any organizations that might have an interest in the submitted work. Other relationships: All authors have declared that there are no other relationships or activities that could appear to have influenced the submitted work.

\section{References}

1. Parkin DM, Bray F, Ferlay J, Pisani P: Global Cancer Statistics, 2002. CA Cancer J Clin. 2005, 55:74-108. 10.3322/canjclin.55.2.74

2. Menhas R, Umer S: Breast cancer among Pakistani women. Iran J Public Health. 2015, 44:586-587.

3. Sohail S, Alam SN: Breast cancer in Pakistan - awareness and early detection. J Coll Physicians Surg Pak. 2007, 17:711-2.

4. Ahmad Z, Idrees R, Fatima S, et al.: Commonest Cancers in Pakistan - Findings and Histopathological Perspective from a Premier Surgical Pathology Center in Pakistan. Asian Pac J Cancer Prev. 2016, 17:10611075. 10.7314/APJCP.2016.17.3.1061

5. Romeiro Lopes TC, Gravena AAF, Demitto MO, et al.: Delay in diagnosis and treatment of breast cancer among women attending a reference service in Brazil. Asian Pac J Cancer Prev. 2017, 18:3017-3023. 10.22034/APJCP.2017.18.11.3017

6. Al-Amri AM: Clinical presentation and causes of the delayed diagnosis of breast cancer in patients with pregnancy associated breast cancer. J Family Community Med. 2015, 22:96-100. 10.4103/2230-8229.155383

7. Gulzar F, Akhtar MS, Sadiq R, Bashir S, Jamil S, Baig SM: Identifying the reasons for delayed presentation of Pakistani breast cancer patients at a tertiary care hospital. Cancer Manag Res. 2019, 11:1087-1096. 10.2147/CMAR.S180388

8. Aziz Z, Sana S, Akram M, Saeed A: Socioeconomic status and breast cancer survival in Pakistani women . J Pak Med Assoc. 2004, 54:448.

9. Majeed AI, Jadoon M, Riazuddin S, Akram J: Awareness and screening of breast cancer among rural areas of Islamabad capital territory, Pakistan. Ann PIMS. 2017, 13:103-107.

10. Khokher S, Qureshi MU, Mahmood S, Sadiq S: Determinants of advanced stage at initial diagnosis of breast cancer in Pakistan: adverse tumor biology vs delay in diagnosis. Asian Pac J Cancer Prev. 2016, 17:759-765. 10.7314/APJCP.2016.17.2.759

11. Maghous A, Rais F, Ahid S, et al.: Factors influencing diagnosis delay of advanced breast cancer in Moroccan women. BMC Cancer. 2016, 16:356. 10.1186/s12885-016-2394-y

12. Smith EC, Ziogas A, Anton-Culver H: Delay in surgical treatment and survival after breast cancer diagnosis in young women by race/ethnicity. JAMA Surg. 2013, 148:516-523. 10.1001/jamasurg.2013.1680

13. Talpur AA, Surahio AR, Ansari A, Ghumro AA: Late presentation of breast cancer: a dilemma . J Pak Med Assoc. 2011, 61:662-666.

14. Baig M, Sohail I, Altaf HN, Altaf OS: Factors influencing delayed presentation of breast cancer at a tertiary care hospital in Pakistan. Cancer Rep. 2019, 2:e1141. 10.1002/cnr2.1141

15. Tiwari V, Yogi V, Ghori HU, et al.: Identifying the factors causing delayed presentation of cancer patients to a Government Medical College of Central India. J Clin Diagn Res. 2015, 9:XC09 - XC12. 10.7860/JCDR/2015/15104.6512

16. Norsa'adah B, Rampal KG, Rahmah MA, Naing NN, Biswal BM: Diagnosis delay of breast cancer and its associated factors in Malaysian women. BMC Cancer. 2011, 11:141. 10.1186/1471-2407-11-141

17. Ogunkorode RS, Holtslander L, Ferguson L, Maree JE, Anonson J, Ramsden VR: Factors influencing the health-seeking behaviors of women with advanced stages of breast cancer in Southwestern Nigeria: an interpretive description study.. Int J Afr Nurs Sci. 2021, 14:100273. 10.1016/j.ijans.2020.100273

18. Khan MA, Hanif S, Iqbal S, Shahzad MF, Shafique S, Khan MT: Presentation delay in breast cancer patients and its association with sociodemographic factors in North Pakistan. Chin J Cancer Res. 2015, 27:288-293. 10.3978/j.issn.1000-9604.2015.04.11

19. Opoku SY, Benwell M, Yarney J: Knowledge, attitudes, beliefs, behaviour and breast cancer screening practices in Ghana, West Africa. Pan Afr Med J. 2012, 11:28.

20. Shamsi U, Khan S, Azam I, et al.: Patient delay in breast cancer diagnosis in two hospitals in Karachi, Pakistan: preventive and life-saving measures needed. JCO Glob Oncol. 2020, 6:873-883. 10.1200/GO.20.00034

21. Khan MA, Ahmed M, Ahmed N, et al.: Treatment navigation pathway and barriers to treatment for cancer patients in Khyber Pakhtunkhwa, Pakistan. J Med Sci. 2017, 25:209-212.

22. Landolsi A, Gahbiche S, Chaafii R, et al.: Reasons of diagnostic delay of breast cancer in Tunisian women (160 patients in the central region of Tunisia). Tunis Med. 2010, 88:894-897.

23. Ermiah E, Abdalla F, Buhmeida A, Larbesh E, Pyrhönen S, Collan Y: Diagnosis delay in Libyan female breast cancer. BMC Res Notes. 2012, 5:452. 10.1186/1756-0500-5-452

24. Grunfeld EA, Hunter MS, Ramirez AJ, Richards MA: Perceptions of breast cancer across the lifespan. J Psychosom Res. 2003, 54:141-146. 10.1016/S0022-3999(02)00522-6 